\title{
CONCRETO COM BORRACHA DE PNEUS APLICADO EM CICLOVIA
}

\section{CONCRETE-RUBBER TYRES USED IN BIKE PATH}

\section{José Franklin Moreira; Vanessa Rosa Pereira Fidelis; João Fernando Dias}

\author{
Universidade Federal de Uberlândia - Faculdade de Engenharia Civil, Uberlândia, \\ MG.E-mail jbrumana@msn.com; vanessarfidelis@gmail.com; jdias@ufu.br
}

\begin{abstract}
RESUMO
Os pneus automotivos apresentam tempo indeterminado de decomposição na natureza representando grande preocupação quanto aos impactos ambientais. Os pneus descartados de forma inadequada podem causar muitos problemas ao acumular água e potencializar a proliferação de vetores de doenças. Quando direcionados aos aterros podem causar instabilidade no maciço devido aos vazios gerados entre eles. No caso da incineração geram material particulado e gases tóxicos tornando-se um risco à saúde. Como parte da constituição dos pneus, a borracha, o nylon e o aço podem se constituir em matéria-prima para outras utilizações. Dessa forma, a destinação final e reutilização ambientalmente corretas, adequadas e seguras são desafios a serem vencidos em todos os segmentos. A construção civil impacta o meio ambiente, mas pode se constituir em sorvedouro de resíduos com a devida comprovação técnica. Para a utilização de resíduos na construção civil encontram-se barreiras, tanto tecnológicas como políticas, tornando incipiente ainda essa prática. Este trabalho é um relato de uma experiência conjunta entre prefeitura municipal, empresa de construção civil e instituição de ensino, para a aplicação de borracha originada do picotamento de pneus automotivos em uma ciclovia. Utilizou-se um concreto com adição de borracha de pneu, em substituição ao agregado miúdo, para a execução de uma ciclovia e verificou-se ser possível sua aplicação em substituição ao concreto convencional. Este equipamento urbano oferece opção de locomoção, fomenta hábitos de vida mais saudáveis e lazer para a população atendida, e pode contribuir para a sustentabilidade.
\end{abstract}

Palavras-chave: Pneu. Borracha. Ciclovia. Concreto com Borracha. Impacto ambiental

\begin{abstract}
Automotive tires have indefinite decomposition in nature and represent great concern about the environmental impacts. The tires disposed of improperly can cause many problems to accumulate water and enhance the proliferation of disease vectors. When directed to landfills can cause instability due to massive voids generated between them. In the case of incineration generate particulate matter and toxic gases becoming a health risk. The constituents of tires as, rubber, nylon and steel may constitute raw material for other uses. Thus, the final destination and environmentally correct, appropriate and safe reuse are challenges to be met in all segments. The construction impacts the environment, but you can use waste with the appropriate technical evidence. For the use of waste in construction are barriers, both technological and political, making this burgeoning practice. This work is an account of a joint experience between city government, construction company and educational institution, for the application of rubber originated automotive tires on a
\end{abstract}


bike path. We used a concrete with addition of tire rubber, replacing the aggregate, for running a bike path and found to their possible application in replacement to conventional concrete. The bike path option offers mobility, fosters habits healthier life and leisure for the population served, and can contribute to sustainability.

Keywords: Tires. Rubber. Bike Path. Concrete with Rubber. Environment Impact.

\section{INTRODUÇÃO}

Estudos realizados pela Empresa de Pesquisa Energética (EPE, 2014), do Ministério das Minas e Energia (MME), resultaram no Plano Nacional de Energia 2050, no qual estimam que a frota de veículos leves atinja, em 2050, cerca de 130 milhões de unidades, representando uma taxa de motorização de aproximadamente 1,7 habitante/veículo. As projeções apontam que a frota de veículos leves crescerá mais rápido do que a população e atingirá 130 milhões de veículos em circulação.

Em relação à produção de pneus, segundo a Associação Nacional da Indústria de Pneumáticos (ANIP, 2014) houve um salto de 54,5 milhões de unidades em 2006 para 68,7 milhões de unidades em 2013. Junto a esses números podem-se levar em consideração os pneus importados e projetar a quantidade desse produto prestes a entrar em uso no mercado.

Diante de um futuro cada vez mais sombrio no campo dos recursos naturais não renováveis e com o aumento em escala quase que exponencial da produção dos mais diversos tipos de resíduos, dentre os quais se destacam aqueles que necessitam de grande tempo para entrar em decomposição, há uma necessidade crescente de reduzir o consumo do primeiro e desenvolver uma solução para o segundo. Olhando para este cenário considerou-se o desafio de desenvolver um concreto que atenda às características mínimas de desempenho para pavimentos, com minimização da utilização de agregados naturais.

Os pneus tem em média uma vida útil de que varia de 40 mil a $100 \mathrm{mil} \mathrm{km}$, dependendo do tipo e das condições de utilização. Após a vida útil, boa parte é descartada ou encaminhada para recapagem, gerando resíduos nos dois casos, com projeção de decomposição em aproximadamente 500 anos.

Segundo Lacerda (2001), um pneu que pesa entre 6 e $10 \mathrm{~kg}$ perde até $10 \%$ de seu peso até o final da vida útil. Os pneus comuns possuem entre 3 a $4 \%$ de aço e o radial possui $10 \%$ de aço em sua estrutura. A quantidade de borracha que pode ser reaproveitada após a vida útil do pneu representa $64,7 \%$ da sua massa.

De acordo com Sukontasukkul e Chaikeaw (2005), a substituição de agregados por borracha para a produção de elementos de concreto para a pavimentação resulta em um material durável, economicamente viável e capaz de absorver mais energia quando submetido a impacto.

Para Giacobbe (2008), no campo da construção civil, a utilização de pneus tem demonstrado ser uma alternativa tecnologicamente interessante, permitindo adequá-la como agregado na produção de concretos de cimento Portland. De acordo com essa autora, uma alternativa para a aplicação desse tipo de resíduo são os concretos destinados à pavimentação, nos quais a borracha adicionada colabora para minimização dos problemas comuns a esse tipo de estrutura, ou seja, comportamento rígido e de fácil fissuração a baixas idades por efeito de retração plástica.

Hernandéz-Olivares et al. (2002), constataram a redução do módulo de elasticidade do concreto com o aumento da quantidade de borracha. Verificaram ainda, quando a tensão máxima é atingida, as fibras de borracha colaboram para evitar a propagação das fissuras e que há um aumento da energia absorvida pela deformação, com consequente diminuição da sonoridade. 
Os especialistas apontam que as bicicletas são a grande saída para as cidades, mas o trânsito seguro de ciclistas depende de uma política de mobilidade sustentável e a construção de ciclovias, ciclofaixas e áreas compartilhadas (VIER, 2009).

$\mathrm{Na}$ Europa e Japão, a maioria dos países já utiliza bicicletários com grande infraestrutura e tecnologia. No Brasil, os destaques são para a cidade do Rio de Janeiro que possui $160 \mathrm{~km}$ de ciclovia e Curitiba que conta com $140 \mathrm{~km}$ de ciclovia. Destaca-se também Porto Alegre que conta com 37\% dos usuários de metrô utilizando bicicleta como meio de locomoção até o mesmo. (MIRANDA, 2006).

Segundo dados da ABRACICLO (2009), o Brasil é o terceiro maior produtor mundial de bicicletas e o $5^{\circ}$ maior consumidor delas e, em 2007 comercializou 5,5 milhões de unidades. Até 2005 , rodavam em território brasileiro mais de 60 milhões de bicicletas.

Abordando as questões relacionadas ao transporte nas grandes cidades, tanto Silva (2009) quanto Fortes (2009), ressaltaram que as ciclovias podem se constituir em uma das soluções para o problema de transporte com contribuições para o meio ambiente ao não contribuir para a emissão de poluentes.

O Desafio Modal ocorrido na cidade de São Paulo, propôs o desafio do menor tempo para se percorrer um percurso. Utilizou-se na avaliação helicóptero, ônibus, trem, metrô, carro, cadeirante e bicicleta, uma pessoa correndo e outra andando, partindo de um mesmo ponto rumo a um mesmo destino. O surpreendente resultado demonstrou que a bicicleta foi melhor em 2008 e 2009, seguida pela moto. Em $4^{\circ}$ lugar ficou o helicóptero. O homem que fez o percurso correndo, chegou antes do carro e o pedestre chegou 10 minutos após (VIER, 2009).

Com tendências para a produção de concretos a ser utilizados em pavimentação aliadas à necessidade de construção de ciclovias que conduzam a hábitos de vida mais saudáveis e redução da emissão de $\mathrm{CO}_{2}$ por parte dos veículos, procurou-se utilizar resíduos de borracha de pneu na produção de concreto e aplicá-lo na construção de uma ciclovia na cidade de Uberlândia.

A cidade escolhida possui apenas 24 mil metros de ciclovias e ciclofaixas espalhadas em 11 bairros e condomínios e não é uma cidade preparada para atender aos ciclistas. Ainda, cerca de $17 \%$ do fluxo total de veículos na área central da cidade é de bicicleta, e a maioria das pessoas que utilizam este tipo de transporte é de baixa renda (SOARES, 2008).

Este trabalho é fruto de uma feliz coincidência de interesses entre agentes da chamada "tríplice hélice", que inclui a academia, representada pela Universidade, as empresas representadas pela Construtora e pela Usina e o Poder Público, através da Secretaria de Obras do município; houve então, na oportunidade, a conjunção de fatores que permitiram juntar a experiência de cada agente nesta ação pioneira e inovadora.

Este trabalho representa uma experiência local para o aproveitamento de resíduo de pneu automotivo, após picotado, na produção de concreto de cimento Portland, em substituição à areia lavada, uma matéria prima natural que, em algumas regiões, já é escassa. Após se conseguir empiricamente produzir o concreto com borracha em laboratório, contou-se com a colaboração de uma empresa concreteira local para a produção do concreto, na quantidade requerida, e partiu-se para a sua aplicação na pavimentação de uma ciclovia. Apresentam-se aqui as principais atividades realizadas e as constatações que permitiram a utilização de um resíduo inservível em concreto para execução de um trecho de ciclovia.

\section{MATERIAIS E MÉTODOS}

O início do trabalho se deu em laboratório, para estudar um traço de concreto com borracha em substituição ao agregado miúdo, com a intenção de ser aplicado na ciclovia. Após o estudo em laboratório, o concreto definitivo (concreto usinado) foi desenvolvido por uma empresa fornecedora de concreto. 


\subsection{Estudo do concreto em laboratório}

Utilizou-se concreto de cimento Portland com um traço denominado "traço-padrão", empírico, a partir do qual foram realizadas as substituições do agregado miúdo pela borracha. Substituiu-se o agregado miúdo por $50 \%, 25 \%$ e $12,5 \%$ em massa do resíduo da borracha respectivamente.

Optou-se pela utilização de borracha de pneu na forma de pequenas tiras em substituição ao agregado miúdo. Ressalta-se que a borracha utilizada não sofreu nenhuma alteração no formato em que se encontra disponível nos vários depósitos desse material, assim aproveita-se o material da forma como está, sem custos com a transformação do mesmo e, ainda, retirando-o da natureza.

Realizou-se ensaio de abatimento de tronco de cone segundo a NBR NM 67:1998 e o ensaio à compressão de corpos-de-prova cilíndricos em 3 idades, 7, 14 e 28 dias respectivamente (NBR 5738:2003; NBR 5739:2007).

Os materiais utilizados na dosagem do traço-padrão foram: cimento Portland CP II E 32; areia lavada média; brita $\mathrm{n}^{\circ} 1$; água e, borracha de pneus picotados em tiras, obtidas diretamente de uma empresa de recapagem de pneus, com tamanho desde pó até o máximo da ordem $2 \mathrm{~cm}$ (ilustração na Figura 1- a); e pedaços irregulares e grandes, que eventualmente encontram-se após o picotamento (Figura 1- a e b).
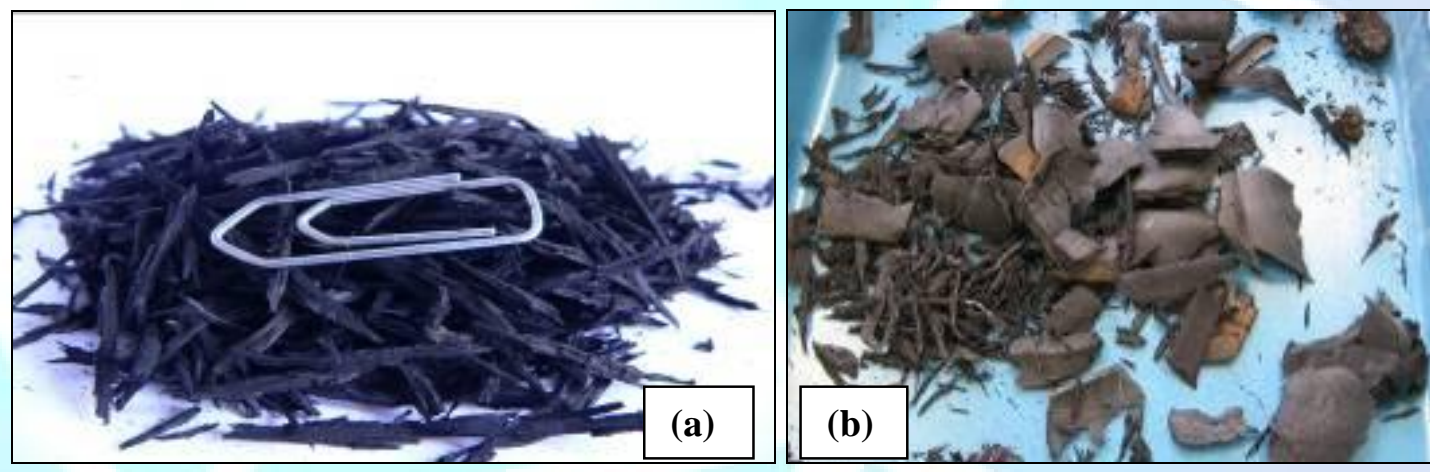

Figura 1. Borracha em tiras (a); pedaços irregulares (b). Fonte: Moreira e Fidelis (2009)

Proporção e características das misturas estudadas: foram preparados três traços de concreto com base no traço-padrão de cimento, agregado graúdo e água (dados do traço apresentados na Tabela 1).

Tabela 1 - Quantidades definidas para o traço-padrão

\begin{tabular}{cccc}
\hline Cimento & Agregado miúdo & Agregado Graúdo & Água \\
\hline $25 \mathrm{~kg}$ & $35 \mathrm{~kg}$ & $50 \mathrm{~kg}$ & $10 \mathrm{~L}$ \\
\hline
\end{tabular}

Variou-se o percentual de agregado miúdo e de borracha adicionada conforme dados indicados na Tabela 2.

Tabela 2 - Traços definidos para o experimento

\begin{tabular}{ccccccc}
\hline Tipo & $\begin{array}{c}\text { Cimento } \\
\text { kg }\end{array}$ & $\begin{array}{c}\text { Agregado Miúdo } \\
\text { kg }\end{array}$ & $\begin{array}{c}\text { Borracha } \\
\text { kg }\end{array}$ & $\begin{array}{c}\text { Agregado graúdo } \\
\text { kg }\end{array}$ & $\begin{array}{c}\text { Água } \\
\text { L }\end{array}$ \\
\hline $50 \%$ & 25 & 17,50 & 17,50 & 50 & 10 \\
\hline $25 \%$ & 25 & 26,25 & 8,75 & 50 & 10 \\
\hline $12,5 \%$ & 25 & 30,625 & 4,375 & 50 & 10 \\
\hline
\end{tabular}


Definidos os traços, seguiu-se para as etapas do processo de mistura e providencias que antecederam à mistura mecânica em betoneira. Para todos os traços foram adotados os mesmos procedimentos seguindo-se a sequência apresentada: 1 . separação do material e pesagem; 2. colocação de parte da água; 3. acréscimo de todo o agregado graúdo; 4. adição do cimento; 5. colocação do agregado miúdo; 5 . acréscimo da borracha; 6 . adição do restante de água previsto na definição do traço; e 7. mistura mecânica em betoneira por aproximadamente 5 minutos.

Com a mistura concluída, determinou-se a consistência através do ensaio do abatimento do tronco de cone, de acordo com o método da norma brasileira NBR NM 67 (ABNT, 1998); na Figura 2 ilustra-se o aspecto da mistura.

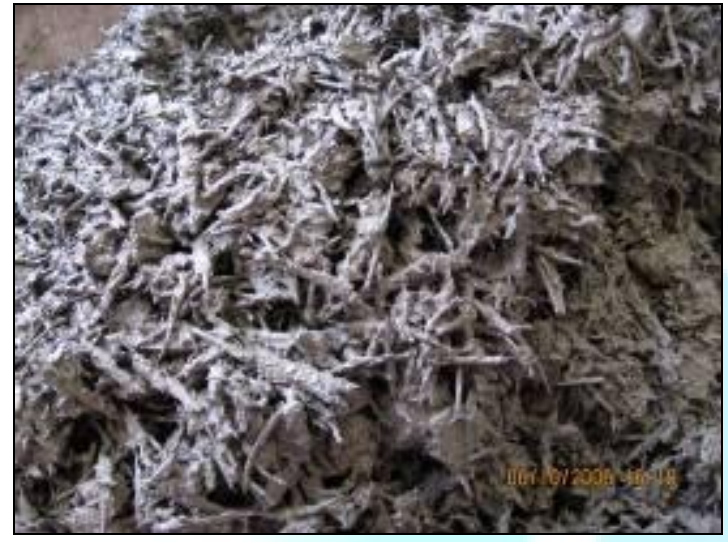

Figura 2. Aspecto da mistura (com 50\% de adição de borracha) Fonte: Moreira; Fidelis (2009)

Para a determinação da resistência à compressão do concreto foram moldados 6 corpos de prova para cada traço, utilizando os procedimentos da norma brasileira NBR 5738 (ABNT, 2007); determinou-se a resistência aos 7, 14, e 28 dias de acordo com os procedimentos da norma NBR 5739 (ABNT, 2003). Os ensaios foram realizados em uma Máquina Universal de Ensaios, eletromecânica e microprocessada EMIC modelo DL60000.

\subsection{Concreto usinado}

A produção do concreto em campo ficou a cargo de uma empresa local, fornecedora de concreto, a qual teve liberdade para alterar o traço sugerido nos estudos no laboratório. Dessa forma, a fornecedora do concreto realizou a dosagem na usina, tendo como referencia os dados do estudo em laboratório.

Ao final foi adotado o percentual de $8,6 \%$ de substituição do agregado miúdo pela borracha. Decidiu-se ainda pela utilização de aditivo que possibilitasse obter a trabalhabilidade desejada e a resistência mínima, com redução do consumo de cimento, pois o traço utilizado em laboratório apresentava maior consumo do aglomerante.

As características definidas para o projeto da ciclovia foram:

- 1.200 m de Ciclovia na cidade de Uberlândia-MG;

- $8 \mathrm{~cm}$ de espessura de concreto e largura variável conforme o trecho considerado;

- $8,6 \%$ de adição de borracha no concreto em substituição ao agregado miúdo;

- $80 \mathrm{~kg}$ de borracha por metro cúbico de concreto;

- Composição de areia fina e areia grossa para melhoria da granulometria e melhor acabamento;

- Utilização do aditivo RX 322N ANCHORTEC, Quartzolit (aditivo plastificante de pega normal para concreto, isento de cloreto, que promove a dispersão do material cimentício, possibilitando a produção de concretos com um maior índice 
de consistência e/ou a redução da água de amassamento, sem afetar significativamente o tempo de pega).

O traço final estabelecido pela fornecedora de concreto está citado na Tabela 7.

\section{RESULTADOS E DISCUSSÃO}

\subsection{Concreto em laboratório - Abatimento do tronco de cone}

Foram produzidos concretos com 50\%, 25\% e 12,5\% de borracha, para os quais se determinou o abatimento do tronco de cone e a resistência mecânica à compressão.

\section{Traço com 50\% de borracha}

Tabela 7 - Traço do concreto utilizado na ciclovia

\begin{tabular}{lcc}
\hline \multicolumn{1}{c}{ Material } & $\mathbf{k g} / \mathbf{m}^{\mathbf{3}}$ & $\mathbf{k g} / \mathbf{k g}$ \\
\hline Cimento CP V Ari - Ciminas & 240 & 1 \\
\hline Areia Fina & 374 & 1,6 \\
\hline Areia Grossa & 554 & 2,3 \\
\hline Brita 1 & 1015 & 4,2 \\
\hline Borracha & 80 & 0,086 \\
\hline Água & 195 & 0,8 \\
\hline Aditivo RX 322N & 0,96 litros & - \\
\hline
\end{tabular}

No primeiro teste para a determinação do abatimento do tronco de cone, verificou-se abatimento nulo (ilustração do aspecto do concreto na Figura 3-a); assim, acrescentou-se mais água de forma lenta e gradual, realizando-se a medição do abatimento, sem ultrapassar o limite de água determinado. Após esse primeiro teste foi acrescentado $300 \mathrm{~mL}$ de água, e em seguida mais 1000 $\mathrm{mL}$. Posteriormente realizou-se outro teste de abatimento, que mais uma vez foi nulo (ilustração na Figura 3-b). Para que o traço padrão inicial não fosse descaracterizado não houve mais acréscimo de água, prosseguindo-se com a moldagem dos corpos-de-prova. 


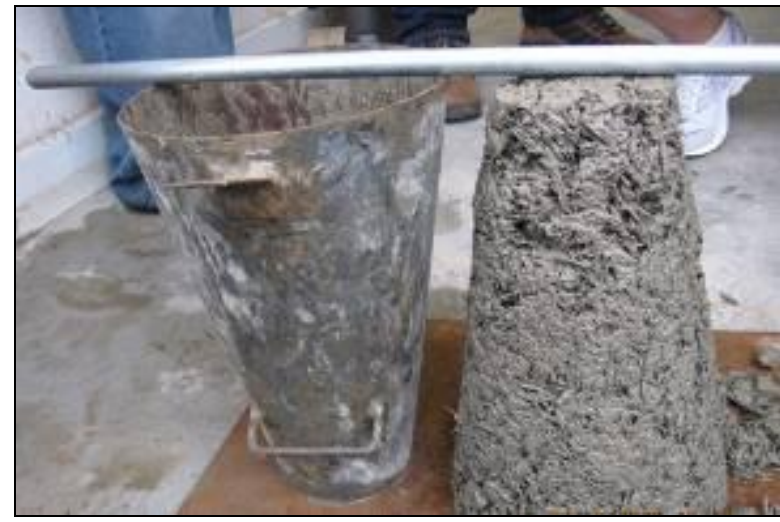

(a) Abatimento nulo do concreto com adição de $50 \%$ de borracha

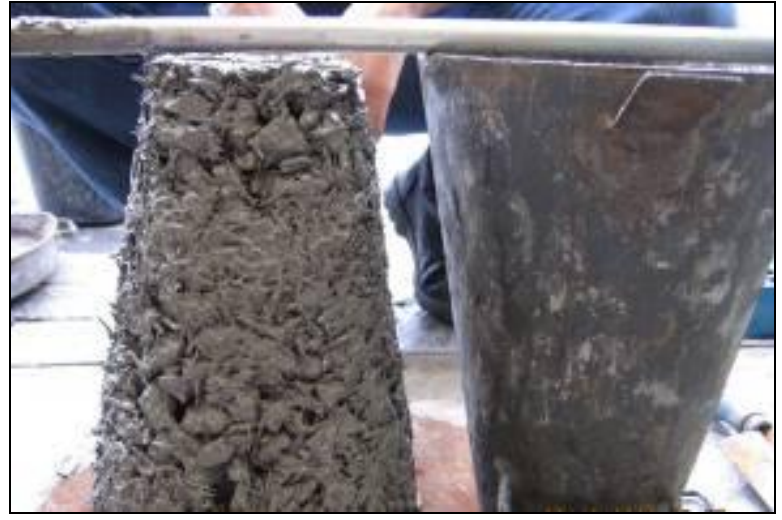

(b) Abatimento nulo com adição de mais água na mesma mistura

Figura 3. Ilustração do abatimento do concreto com adição de $50 \%$ borracha.

Fonte: Moreira e Fidelis (2009)

\section{Traço com $25 \%$ de borracha}

No primeiro teste para avaliação da trabalhabilidade verificou-se um abatimento de $35 \mathrm{~mm}$, sendo que o aspecto do concreto se encontra ilustrado na Figura 4- a. Em seguida acrescentou-se mais $800 \mathrm{~mL}$ de água e constatou-se o valor de $60 \mathrm{~mm}$ para o abatimento (Figura 4- b), e posteriormente, prosseguiu-se com a moldagem dos corpos-de-prova.

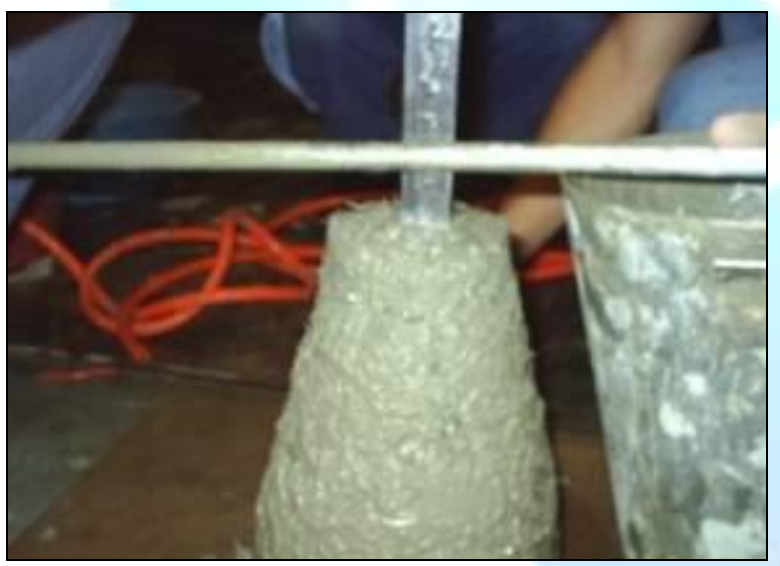

(a) Abatimento de $35 \mathrm{~mm}$ do concreto com $25 \%$ de borracha

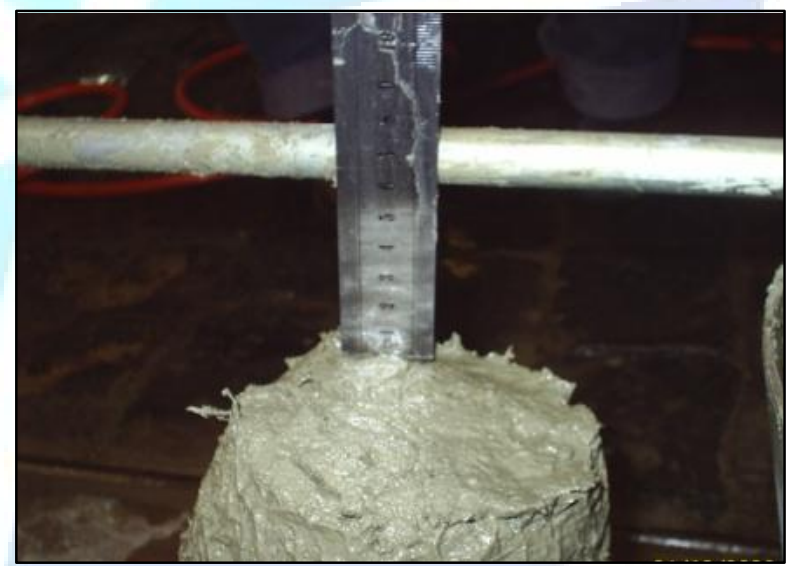

(b) Abatimento de $60 \mathrm{~mm}$ com $25 \%$ de borracha

Figura 4. Ilustração do abatimento do concreto com adição de $25 \%$ de borracha Fonte: Moreira e Fidelis (2009)

\section{Traço com $12,5 \%$ de borracha}

No primeiro teste para avaliação da trabalhabilidade verificou-se abatimento da ordem de $10 \mathrm{~mm}$ (Figura 5- a). Em seguida acrescentou-se $500 \mathrm{~mL}$ de água, obtendo-se um abatimento de $65 \mathrm{~mm}$ (Figura 5- b). Posteriormente, realizou-se a moldagem dos corpos-de-prova. 


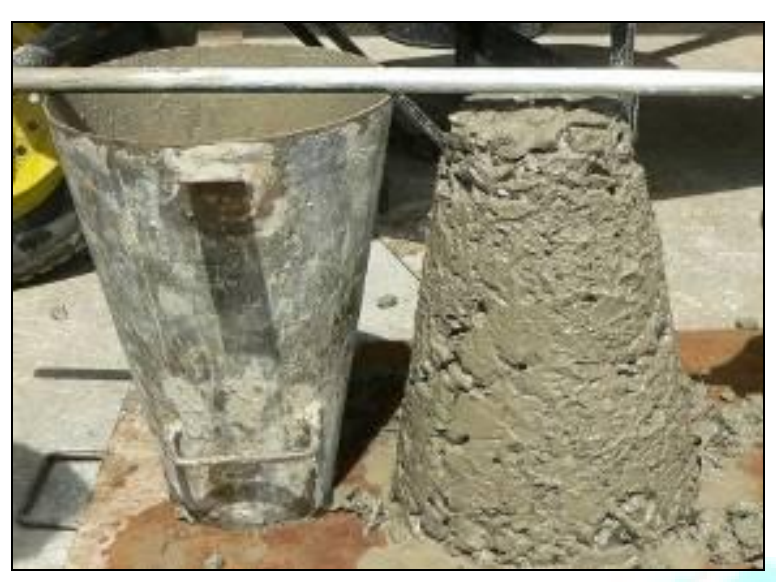

(a) Abatimento de $10 \mathrm{~mm}$ do concreto com $12,5 \%$ de borracha

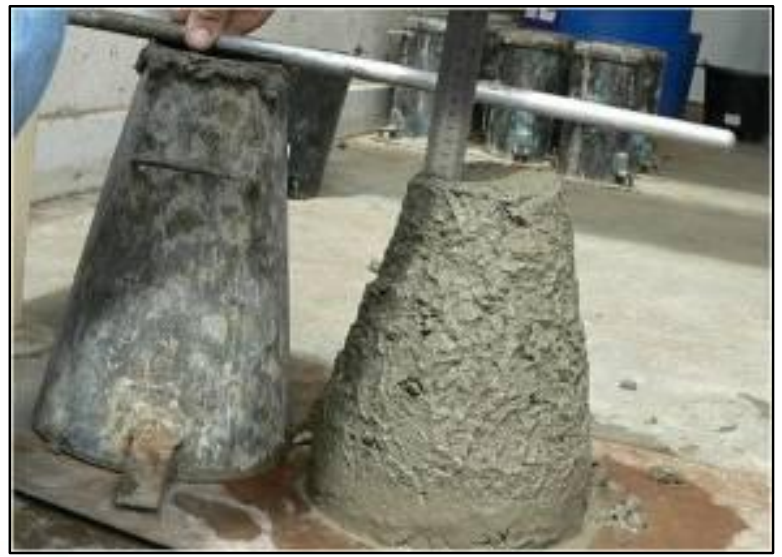

(b) Abatimento de $65 \mathrm{~mm}$ do concreto com de $12,5 \%$ de borracha

Figura 5. Ilustração do abatimento do concreto com adição de $25 \%$ de borracha Fonte: Moreira e Fidelis (2009)

\subsection{Concreto em laboratório - Resistência à compressão}

$\mathrm{Na}$ Tabela 3 apresentam-se as massas dos corpos de prova e a relação percentual indicativa de quanto mais leve se tornou o concreto com borracha em comparação com o de referencia (sem borracha). Nas Tabelas 4, 5 e 6 apresentam-se os resultados da resistência à compressão.

Tabela 3 - Tipo de concreto $\times$ peso

\begin{tabular}{ccc}
\hline $\begin{array}{c}\text { Borracha } \\
\mathbf{\%}\end{array}$ & $\begin{array}{c}\text { Peso } \\
\mathbf{k g}\end{array}$ & $\begin{array}{c}\text { Redução do peso do concreto } \\
\mathbf{\%}\end{array}$ \\
\hline 50 & 9,885 & 23 \\
\hline 25 & 10,674 & 16 \\
\hline 12,5 & 11,848 & 7 \\
\hline 0 & 12,775 & - \\
\hline
\end{tabular}

Tabela 4 - Resistência à compressão do concreto com 50\% de borracha

\begin{tabular}{cccc}
\hline Idade & $\begin{array}{c}\text { Corpo de prova } \\
\mathbf{n}^{\mathbf{0}}\end{array}$ & $\begin{array}{c}\text { Massa } \\
(\mathbf{k g})\end{array}$ & $\begin{array}{c}\text { Tensão de ruptura } \\
(\mathbf{M P a})\end{array}$ \\
\hline \multirow{2}{*}{7 dias } & 26 & 10,160 & 2,50 \\
\cline { 2 - 4 } & 30 & 10,275 & 3,00 \\
\hline \multirow{2}{*}{14 dias } & 23 & 9,920 & 3,00 \\
\hline \multirow{2}{*}{28 dias } & 39 & 9,840 & 3,50 \\
\cline { 2 - 4 } & 42 & 9,630 & 4,00 \\
\hline
\end{tabular}


Tabela 5 - Resistência à compressão do concreto com $25 \%$ de borracha

\begin{tabular}{cccc}
\hline Idade & $\begin{array}{c}\text { Corpo de prova } \\
\mathbf{n}^{\mathbf{0}}\end{array}$ & $\begin{array}{c}\text { Massa } \\
(\mathbf{k g})\end{array}$ & $\begin{array}{c}\text { Tensão de ruptura } \\
(\mathbf{M P a})\end{array}$ \\
\hline \multirow{2}{*}{7 dias } & 6 & 10,970 & 6,80 \\
\cline { 2 - 4 } & 10 & 10,720 & 6,90 \\
\hline \multirow{2}{*}{14 dias } & 3 & 10,810 & 7,00 \\
\hline \multirow{2}{*}{28 dias } & 7 & 10,730 & 7,00 \\
\cline { 2 - 4 } & 4 & 10,500 & 8,00 \\
\hline
\end{tabular}

Tabela 6 - Resistência à compressão do concreto com 12,5\% de borracha.

\begin{tabular}{cccc}
\hline Idade & $\begin{array}{c}\text { Corpo de prova } \\
\mathbf{n}^{\mathbf{0}}\end{array}$ & $\begin{array}{c}\text { Massa } \\
(\mathbf{k g})\end{array}$ & $\begin{array}{c}\text { Tensão de ruptura } \\
\text { (MPa) }\end{array}$ \\
\hline \multirow{2}{*}{7 dias } & 5 & 11,870 & 11,00 \\
\cline { 2 - 4 } & 6 & 11,790 & 13,00 \\
\hline \multirow{2}{*}{14 dias } & 1 & 11,890 & 15,10 \\
\hline \multirow{2}{*}{28 dias } & 2 & 11,880 & 13,70 \\
\cline { 2 - 4 } & 7 & 11,780 & 16,00 \\
\hline
\end{tabular}

\subsection{Concreto em laboratório - Análise final}

À medida que se adicionou borracha a trabalhabilidade do concreto piorou, inferindo-se que devido ao travamento das partículas proporcionando mais baixo abatimento; verificou-se, ainda, que a quantidade de água necessária para a mistura foi reduzida com a diminuição da quantidade de borracha (efeito do menor travamento neste caso). Constatou-se, portanto a influência negativa do aumento da quantidade de borracha na trabalhabilidade e a necessidade, também negativa, de mais água de amassamento para tornar a mistura trabalhável.

Em relação à resistência à compressão verificou-se queda considerável nos valores obtidos, à medida que se aumentou o conteúdo de borracha. Pode-se inferir que a queda ocorreu devido ao aumento do consumo de água para atingir o mesmo abatimento, e também por que o empacotamento granular menos eficiente com a inclusão da borracha, apresentou vazios e descontinuidades no concreto.

Observou-se que os corpos de prova de concreto com borracha ao se romperem não desagregam da mesma maneira como ocorre com o concreto sem borracha. Verificou-se também a queda na massa final do concreto e quanto ficou mais leve o concreto com borracha em relação ao concreto sem borracha.

Na Figura 6 relacionam-se todas as variáveis do experimento em laboratório, quais sejam, a quantidade de borracha misturada ao concreto, a massa final das peças de concreto, o quanto mais leve ficou o concreto em relação a um concreto convencional sem adição de borracha e a resistência à compressão final obtida aos 28 dias.

\subsection{Aplicação do concreto usinado na ciclovia - Análise final}

O experimento com o concreto no laboratório contribuiu como parâmetro e orientação para a produção do concreto na usina, para posterior aplicação na execução da ciclovia.

Foram realizadas modificações em relação ao concreto estudado no laboratório e resultaram em um traço diferente, pois os agregados e o cimento eram diferentes, além da utilização de aditivo. 
Após a locação da pista e posicionamento de sarrafos de madeira serrada para delimitação da área a ser concretada, o concreto foi lançado e compactado manualmente. O sarrafeamento e acabamento foram realizados com régua metálica de alumínio e desempenadeira manual (Figura 7).

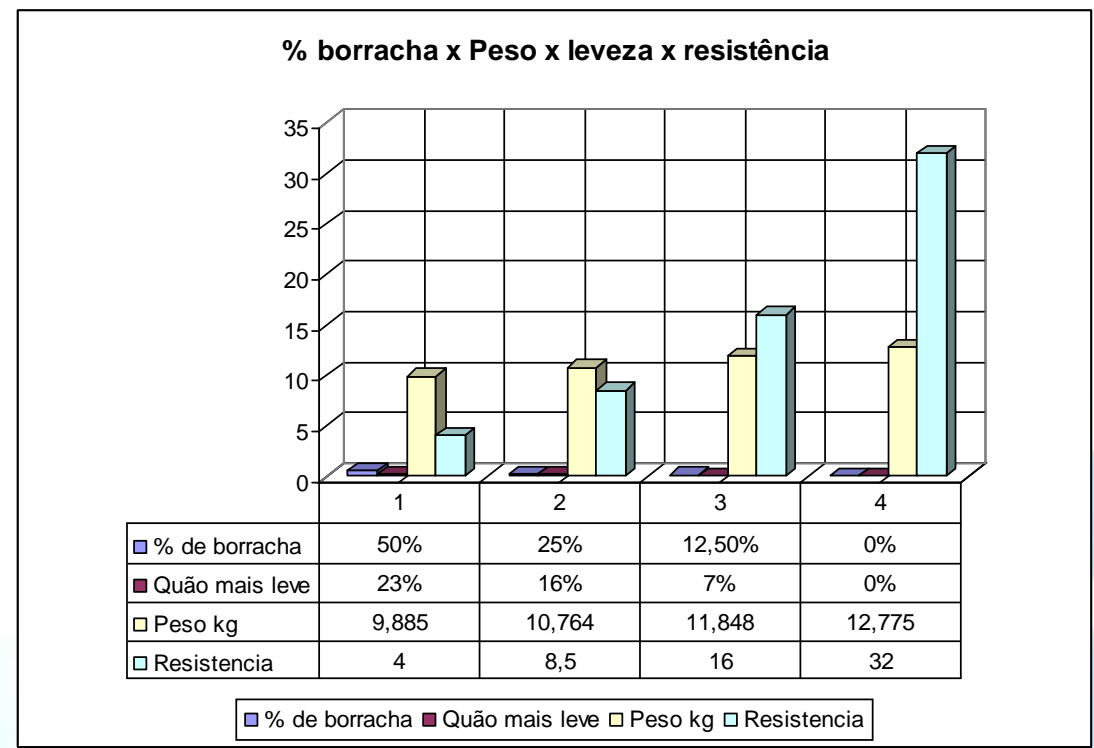

Figura 6. Resultados das variáveis do experimento realizado neste estudo.
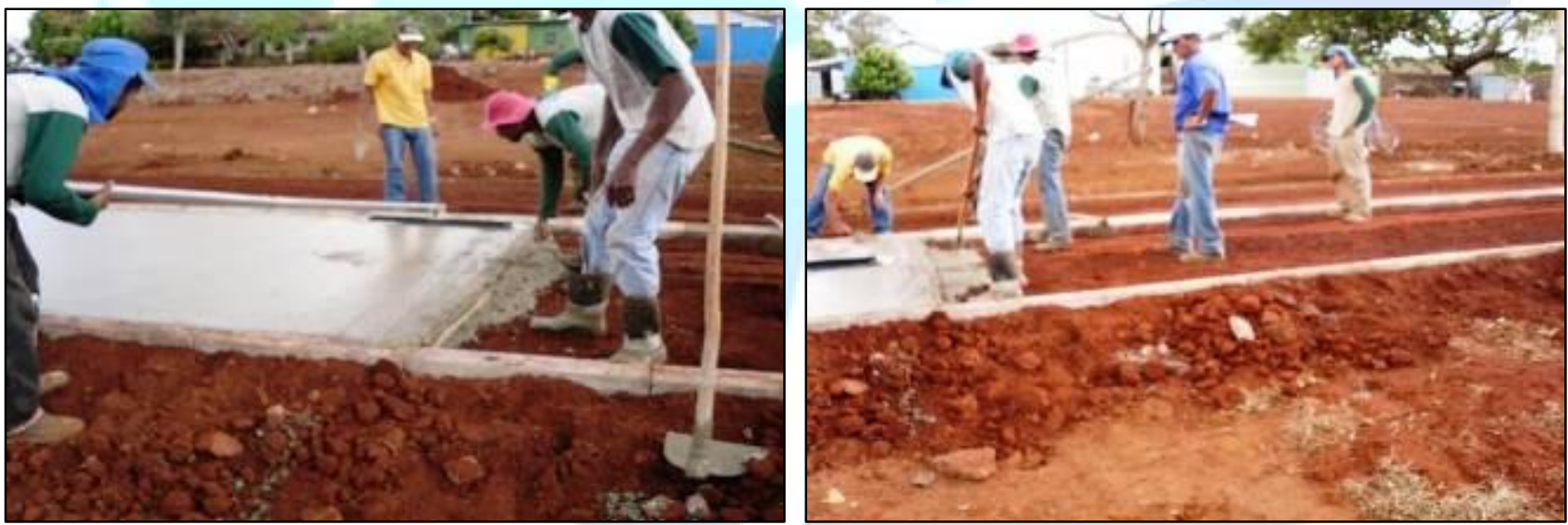

Figura 7. Aplicação e sarrafeamento do concreto. Fonte: Moreira e Fidelis (2009)

$\mathrm{O}$ aspecto final do pavimento da ciclovia é bem parecido com um pavimento em concreto convencional, somente olhando-se o piso bem próximo é que se identifica a presença das fibras de borracha (Figura 8). 


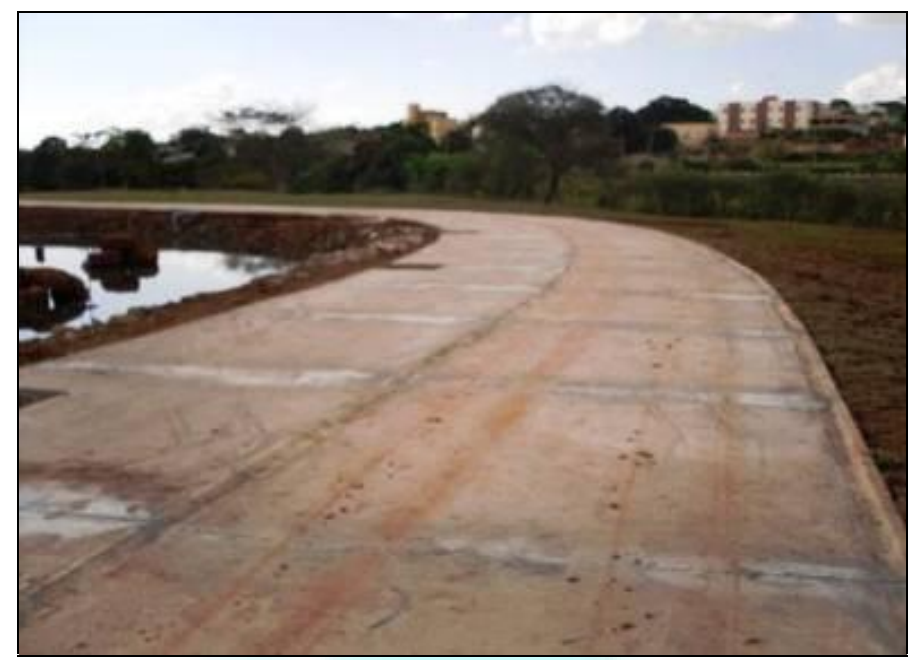

Figura 8. Vista geral do pavimento da ciclovia às Margens do Rio Uberabinha, Uberlândia-MG Fonte: Moreira e Fidelis; (2009)

Com a produção e aplicação do concreto na ciclovia, verificou-se que é possível a utilização da borracha de pneu em substituição ao agregado miúdo do concreto com resultado satisfatório, tanto na produção quanto na aplicação do concreto na obra.

Para a proposta de pavimentação de ciclovia, a aplicação demonstrou-se aceitável, pois não exige resistência elevada à compressão e espera-se durabilidade compatível com o tipo de construção.

Com a utilização de $80 \mathrm{~kg}$ de borracha por metro cúbico de concreto e baseando-se nas informações levantadas por Lacerda (2001), que indica o reaproveitamento de 64,7\% da borracha do pneu ao término de sua vida útil, e ainda o peso médio de um pneu de carro de passeio (de 7,9 $\mathrm{kg}$ ), chegou-se ao consumo de aproximadamente 3000 pneus de carros de passeio na execução da ciclovia.

\section{CONCLUSÕES}

O intuito deste trabalho foi divulgar uma experiência de aplicação de pneus usados em concreto para a pavimentação de uma ciclovia. Um trabalho dessa natureza guarda dificuldades de realização, desde as próprias ao estudo tecnológico, como também a conjunção dos esforços dos segmentos envolvidos com a ideia. A conjunção dos esforços entre a universidade, as empresas e a secretaria municipal permitiu a realização desta experiência.

Do ponto de vista tecnológico, em relação ao concreto com substituição de areia pela borracha, verificou-se perda considerável da resistência à compressão. No entanto, a resistência obtida foi considerada compatível com a necessidade do serviço executado. Ressalta-se que o concreto, com as características obtidas, não seria adequado para utilização em elementos estruturais, para os quais outros requisitos seriam necessários.

Com relação às dificuldades de aplicação do concreto com borracha, verificou-se que não se configurou em um fator limitante, sendo possível aplicá-lo com os mesmos equipamentos rotineiramente utilizados para emprego do concreto convencional.

Do ponto de vista ambiental, mesmo que timidamente, constatou-se que é possível reaproveitar os pneus automotivos ao término de sua vida útil com o processamento adequado. 


\section{REFERÊNCIAS}

ABRACICLO - Associação Brasileira dos Fabricantes de Motocicletas, Ciclomotores, Motonetas, Bicicletas e Similares. Dados do setor - bicicletas. Disponível em:

<http://www.abraciclo.com.br>. Acesso em: 25 nov. 2009.

ASSOCIAÇÃO BRASILEIRA DE NORMAS TÉCNICAS. NBR 5738: Concreto - Procedimento para modelagem e cura de corpos-de-prova. Rio de Janeiro, 2003.

. NBR 5739: Concreto - Ensaios de compressão de corpos-de-prova cilíndricos. Rio de Janeiro, 2007.

. NBR NM 67: Concreto - Determinação da consistência pelo abatimento do tronco de cone. Rio de Janeiro, 1998.

ANIP - ASSOCIAÇÃO NACIONAL DA INDÚSTRIA DE PNEUMÁTICOS. Produção. 2013. http://www.anip.com.br/?cont=conteudo\&area=32\&titulo_pagina=Produ\%E7\%E3o. Acesso em 14 de agosto de 2014.

EPE - Empresa de Pesquisa Energética (Ministério de Minas e Energia, Brasil). Cenário econômico 2050. Série Estudos Econômicos Nota Técnica DEA 12/14. Rio de Janeiro. agosto de 2014. Disponível em: <http://www.epe.gov.br/Estudos/Documents/PNE2050_Premissas\%20 econ\%C3\%B4micas\%20de\%20longo\%20prazo.pdf >. Acesso em: 14/08/2014.

FORTES, M. No Dia Mundial sem Carro, ministro promete mais investimentos em ciclovias, Agência Brasil, Brasília, 22 set. 2009. Ambiente. 10h39. Disponível em:

<http://www.correiobraziliense.com.br/app/noticia182/2009/09/22/brasil,i=143606/NO+DIA+MU NDIAL+SEM+CARRO+MINISTRO+PROMETE+MAIS+INVESTIMENTOS+EM+CICLOVIAS .shtmL>. Acesso em: 25 nov. 2009.

GIACOBBE, S. Estudo do comportamento físico-mecânico do concreto de cimento portland com adição de borracha de pneus. 2008. 106 f. Dissertação (Mestrado em Engenharia Civil e Urbana), Escola Politécnica da Universidade de São Paulo, São Paulo, 2008.

HERNANDÉZ-OLIVARES, F., BARLUENGA, G., BOLLATI, M., WITOSZEK, B., Static and dynamic behavior of recycled tyre rubber-filled concrete. Cement and Concrete Research, v.32, pp.1587-1596, 2002.

LACERDA, L.P. de. Pneus descartados no Brasil - Subsídios para uma reflexão sobre o problema na Bahia. 2001. 59 f. Monografia (Especialização em Gerenciamento e Tecnologias Ambientais na Indústria - Ênfase em Produção Limpa), Escola Politécnica da Universidade Federal da Bahia, Salvador, 2001.

MIRANDA, A. Especialista mostra, na Trensurb, a importância das ciclovias e bicicletários nas grandes cidades, Trensurb, São Paulo, 05 jan. 2006. Notícias. Disponível em: <http://www.trensurb.com.br/php/noticias/noticias_detalhe.php?pNoticia_id=421\&pDestaque=0 > Acesso em: 25 de nov. 09. 
SILVA, C. Futuro das cidades é restringir automóveis, apontam especialistas, Rede Brasil Atual, São Paulo, 25 set. 2009. Ambiente. 17h23. Disponível em:

$<$ http://www.redebrasilatual.com.br/temas/ambiente/futuro-das-cidades-e-restringir-automoveisapontam-especialistas/view>. Acesso em: 25 nov. 2009.

SOARES, R. Cidade carece de estrutura para atender os ciclistas, Correio de Uberlândia, MG, 21 mai. 2008. Notícias. 01h09. Disponível em:

<http://www.correiodeuberlandia.com.br/texto/2007/06/03/28114/cidade_carece_de_estrutura_para _atender_os_ciclistas.htmL>. Acesso em: 09 dez. 2009.

\section{SUKONTASUKKUL, P.; CHAIKAEW, C. Concrete Pedestrian Block Containing Crumb}

Rubber from Recycled Tires. Thailand: Thammasalnt University, v. 10, n. 2 , 2005.

VIER, S. Futuro das cidades é restringir automóveis, apontam especialistas, Rede Brasil Atual, São Paulo, 25 set. 2009. Ambiente. 17h23. Disponível em:

$<$ http://www.redebrasilatual.com.br/temas/ambiente/futuro-das-cidades-e-restringir-automoveisapontam-especialistas/view>. Acesso em: 25 nov. 2009. 